\title{
Stabilization of the Alleged 'Bishomoaromatic' Bicyclo[3.2.1]octa-2,6-dienyl Anion by Counterion Interactions and by Hyperconjugation
}

\section{Paul von Ragué Schleyer,*a Elmar Kaufmann,a Alexander J. Kos,b Herbert Mayr, ${ }^{\circ}$ and Jayaraman Chandrasekhard}

a Institut für Organische Chemie der Friedrich-Alexander-Universität Erlangen-Nürnberg, Henkestrasse 42, D-8520

Erlangen, Federal Republic of Germany

b Molecular Design MDL AG, Wallstrasse 8, CH-4002 Basel, Switzerland

c Institut für Chemie, Medizinische Universität zu Lübeck, Ratzeburger Allee 160, D-2400 Lübeck 1, Federal Republic of Germany

d Department of Organic Chemistry, Indian Institute of Science, Bangalore 560 012, India

Hyperconjugation and inductive effects, rather than homoaromaticity, are responsible for the stabilization of the title anion in the gas phase; interaction of the double bond with the $\mathrm{Li}^{+}$gegenion in the endo geometry contributes additionally in solution.

Does the bicyclo[3.2.1]octa-2,6-dienyl anion (1) owe its enhanced stability ${ }^{1}$ [equation (1)] to homoaromaticity? ${ }^{2}$ While the symmetry in this six- $\pi$-system is ideal for interaction between the olefin and allyl anion moieties, ${ }^{2}$ the resulting stabilization may be negligible because the two fragments are too far apart (poor orbital overlap). ${ }^{3}$ The challenge of qualitative ${ }^{1,2}$ by quantitative theory ${ }^{3}$ has led to many further investigations and current debate. ${ }^{1 b, c, 4-8}$

The principal new experimental results said to favour homoconjugation are energetic comparisons with model compounds in the gas phase ${ }^{1 \mathrm{c}}$ and in solution, ${ }^{1 \mathrm{~b}}$ as well as some ${ }^{5 a, c}$ of the analyses of n.m.r. data. ${ }^{5}$ We contest these interpretations by considering other factors which can contribute to the stabilization of (1): hyperconjugation and gegenion interactions. The effects of hyperconjugation have<smiles>C1=CC2CCC1C2</smiles><smiles>C1=CC2C=CC1C2</smiles>
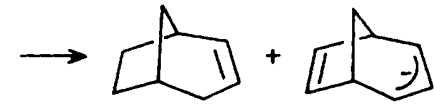

$\Delta E=-4.2 \mathrm{kcal} / \mathrm{mol}(\mathrm{STO}-3 \mathrm{G})^{3}$

$\Delta E=+0.6 \mathrm{kcal} / \mathrm{mol}(\mathrm{MNDO})^{3}$

$\Delta G=-9.5 \pm 2.0 \mathrm{kcal} / \mathrm{mol}$ (gas phase) $^{1 \mathrm{c}}$

$\Delta G=-12.2 \mathrm{kcal} / \mathrm{mol}$ (solution, Cs salt) ${ }^{1 \mathrm{~b}}$

not been assessed adequately in the model systems studied in the gas phase, 1c while gegenion interactions have not been<smiles>C=CC(C)Cl</smiles>

(3)<smiles>[Tl]C1=CCC2CCC1C2</smiles><smiles>[C+]1=CC2C=CCC1C2</smiles>

33.6 $\Delta H_{1}(\mathrm{MNDO}) /-6.3$ $\mathrm{kcal} / \mathrm{mol}$
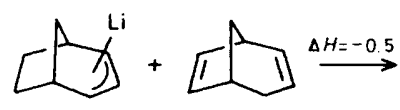

33.6

$\Delta H_{f}(\mathrm{MNDO}) /-3.1$ $\mathrm{kcal} / \mathrm{mol}$<smiles>C1=CC2C=CC1C2</smiles>

(6)<smiles>[CH2+]C1=CC2C=CC1C2</smiles>

(5) \section{.}


considered in solution phase studies. $1 \mathrm{~b}, 5 \mathrm{We}$ now provide evidence for the former by means of $a b$ initio calculations on a model system and for the latter through MNDO calculations on the lithium salt of (1). This lithium compound has been characterized recently by an $X$-ray study, ${ }^{6}$ but no firm conclusions regarding the electronic structure could be drawn. Analysis of its wave function as well as that of (1) at the $a b$ initio CASSCF level led to the conclusion that homoaromaticity is unimportant in this system. ${ }^{7}$ However, neither the magnitude of the metal-olefin interaction nor the gegenion effect on the relative acidities were evaluated, e.g. by means of equations (1)-(3). In the present paper we calculate the quantities using the MNDO method, ${ }^{9}$ which has been employed successfully for interpreting and predicting numerous organolithium structures. ${ }^{10}$

Since $\mathrm{C}\left(\mathrm{sp}^{2}\right)$ atoms are more electronegative than $\mathrm{C}\left(\mathrm{sp}^{3}\right)$, the allyl anion system in (1) will be stabilized, relative to (2), by the double bond. Both hyperconjugation ${ }^{11}$ with the more electron-accepting $\mathrm{C}(1)-\mathrm{C}(7)\left(\mathrm{sp}^{2}\right)$ and $\mathrm{C}(5)-\mathrm{C}(6)\left(\mathrm{sp}^{2}\right)$ bonds and inductive effects are responsible. ${ }^{3}$ These influences are demonstrated nicely by model $a b$ initio calculations on the homoallyl anion (3) held in a conformation which precludes homoconjugation but favours negative hyperconjugation. At the 4-31+G//3-21G level which provides accurate proton affinities, ${ }^{12}(3)$ is calculated to be stabilized relative to the n-butyl anion by $6.6 \mathrm{kcal} / \mathrm{mol}(1 \mathrm{cal}=4.184 \mathrm{~J})$. The orientations of the carbanion centres in (1) are also favourable for hyperconjugation with the $\beta-\mathrm{C}\left(\mathrm{sp}^{3}\right)-\mathrm{C}\left(\mathrm{sp}^{2}\right)$ bonds, but this is not true in $(\mathbf{4})$, one of the model systems examined by Lee and Squires; ic (4) can benefit only from the inductive effect of the double bond. Because of unfavourable strain and repulsive electronic effects, $(5)^{1 \mathrm{c}}$ may not be satisfactory as a model for (1) either.

Another factor which contributes in solution is revealed by MNDO calculations: the more favourable gegenion interactions in (1) over those in (2). Bicyclo[3.2.1] octa-2,6-dienyllithium is predicted to be most stable in the endo form (6), since this benefits from $\pi$ chelation of $\mathrm{Li}^{+}$by the double bond. The MNDO structure of (6) (Figure 1) shows overall agreement with the $X$-ray structure of (6) solvated by $N, N, N^{\prime}, N^{\prime}$-tetramethylethylenediamine (TMEDA), ${ }^{6}$ and is remarkably close to the CASSCF minimal basis set geometry of the unsolvated compound. ${ }^{7}$ Although the calculated MNDO bond lengths are somewhat too long, the distortions of the dihedral angles involving the ring planes, commented on by Köhler et al., ${ }^{6}$ are predicted rather well. Evidence for bishomoaromaticity in the $X$-ray structure can therefore be examined critically using our computational model.

Three structural features are of interest: the $\overline{\mathrm{CC}}$ bond lengths in the allyl anion moiety and in the olefinic fragment, and the separation between these units. The $X$-ray bond lengths in the allyl fragment of $(6)$ are quite normal $(1.39 \AA)^{13}$ showing no evidence for homoconjugation. The slight lengthening of the $C(6)-C(7)$ bond $(1.354 \AA)$ is also similar to the elongation $(0.01-0.02 \AA)$ calculated for the $\mathrm{C}=\mathrm{C}$ bond in ethylene, complexed with $\mathrm{Li}^{+}$or $\mathrm{RLi} .{ }^{14} \mathrm{We}$ assert that the experimental $\mathrm{C}(2)-\mathrm{C}(7)$ and $\mathrm{C}(4)-\mathrm{C}(6)$ separations $(2.37 \AA)$ are still too large for effective overlap between the interacting fragments. While Lindh et al. ${ }^{7}$ concur with us, Brown et al. ${ }^{8}$ have argued on the basis of STO-3G calculations that orbital energies and charge distributions of isolated ethylene and allyl anion units, held at such distances, indicate significant interaction, but the effects on the total energies are destabilizing. A more direct way to quantify the electronic effects in these systems is to consider the relative proton affinities and lithium chelation energies of (1) and (2) by means of equations (2) and (3).

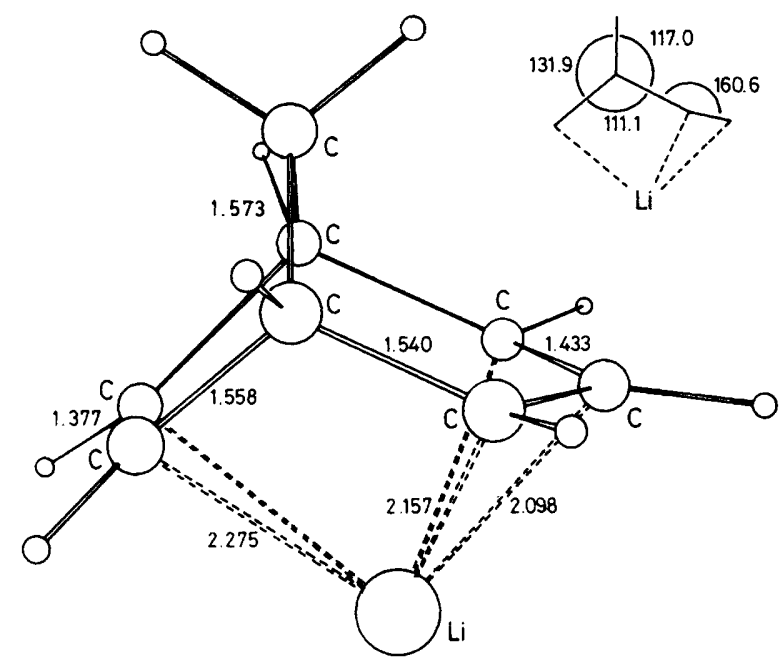

Figure 1. Computer plot of the MNDO structure of (6), which may be compared with the $X$-ray structure. ${ }^{6}$ The inset shows the angles between the projected ring planes. Carbon-lithium distances are underestimated by MNDO, especially when $n$-donor ligand interactions are not included.

endo-(6) is nearly $9 \mathrm{kcal} / \mathrm{mol}$ more stable than the exoisomer (7). The energy of equation (2) exceeds that of equation (1) (MNDO) by $6.5 \mathrm{kcal} / \mathrm{mol}$ and that of equation (3) by $5.4 \mathrm{kcal} / \mathrm{mol}$. These are measures of the additional $\mathrm{Li} \pi$ chelation energy and should correct for the underestimation of the energy of equation (1) by MNDO. The MNDO lithium parameterization is known to overestimate the strengths of $\mathrm{Li} \cdots \mathrm{C}$ (and $\mathrm{Li} \cdots \mathrm{H}$ ) interactions; ${ }^{10,14}$ e.g., the MNDO $\mathrm{C}_{2} \mathrm{H}_{4}-\mathrm{LiH}$ complexation energy $(23.5 \mathrm{kcal} / \mathrm{mol})$ exceeds the $3-21 \mathrm{G}$ ( $a b$ initio) value $(12.9 \mathrm{kcal} / \mathrm{mol}) .{ }^{14,15}$ However, the MNDO isobutene- $\mathrm{Li}^{+}$interaction energy $(34 \mathrm{kcal} / \mathrm{mol})$ is not much larger than that determined experimentally in the gas phase $(28 \mathrm{kcal} / \mathrm{mol}) .{ }^{16}$ The $\pi$ chelation energy is expected to attenuate somewhat with the heavier alkali metals, but significant $\pi$ interactions, as are found in numerous $X$-ray structures, ${ }^{17}$ still should be present.

The calculated stabilization energies provide a rationale for the observed variation of the relative stabilities of (1) and (2) in the gas phase and in solution. While energy differences are generally attenuated in solution, the energy corresponding to the measured $\mathrm{p} K_{\mathrm{a}}$ difference of the Cs salts of (1) and (2) in cyclohexylamine solvent ${ }^{1 b}$ exceeds that of the gas phase (ion cyclotron resonance) value ${ }^{1 \mathrm{cc}}$ by more than $2.7 \pm 2 \mathrm{kcal} / \mathrm{mol}$ (equation 1). Our higher estimates for the greater stabilization of the Li salts, (6) vs. (7), seem quite reasonable.

Lithium gegenion interactions (and those of other alkali metals), in addition to providing a significant energetic effect, will also lead to geometry changes in the carbanions that may influence n.m.r. parameters significantly. $5,6,13 \mathrm{~b}$ Interpretation of these data in terms of bishomoaromatic charge delocalization therefore is obscured.

In conclusion, negative hyperconjugation and inductive effects contribute significantly to the stabilization of (1) in the gas phase; counterion effects, e.g. in (6), contribute additionally in solution. ${ }^{18}$ Bishomoaromaticity can be, at best, only a minor factor influencing the behaviour of these systems.

This work was supported by the Deutsche Forschungsgemeinschaft and the Fonds der Chemischen Industrie. We thank M. Christl, R. R. Squires, F. H. Köhler, R. Lindh, and 
P. Ahlberg for providing manuscipts prior to publication and discussions.

Received, 1st April 1986; Com. 411

\section{References}

1 (a) J. M. Brown and J. L. Occolowitz, Chem. Commun., 1965, 376; J. Chem. Soc. B, 1968, 411; J. M. Brown, Chem. Commun., 1967, 638; S. Winstein, M. Ogliaruso, M. Sakai, and J. M. Nicholson, J. Am. Chem. Soc., 1967, 89, 3656; (b) W. N. Washburn, J. Org. Chem., 1983, 48, 4287; (c) R. E. Lee and R. R. Squires, J. Am. Chem. Soc, , 1986, 108, 5078.

$2 \mathrm{~S}$. Winstein, in 'Aromaticity: An International Symposium' (Sheffield, 1966), Special Publication No. 21, The Chemical Society, 1967, p. 55; M. J. Goldstein and R. Hoffmann, J. Am. Chem. Soc., 1971, 93, 6193.

3 E. Kaufmann, H. Mayr, J. Chandrasekhar, and P. v. R. Schleyer, J. Am. Chem. Soc., 1981, 103, 1375; J. B. Grutzner and W. L. Jorgensen, ibid., 1981, 103, 1372.

4 K. N. Houk, R. W. Gandour, R. W. Strozier, N. G. Rondan, and L. A. Paquette, J. Am. Chem. Soc., 1979, 101, 6797. Also see: D. Cremer, E. Kraka, T. S. Slee, R. W. F. Bader, C. D. H. Lau, T. T. Nguyen-Dang, and P. J. MacDongall, J. Am. Chem. Soc., 1983, 105, 5069; R. D. Bach, G. J. Wolber, and H. B. Schlegel, ibid., $1985,107,2837$.

5 (a) M. Christl and D. Brückner, Chem. Ber., 1986, 119, 2025. For other recent n.m.r. studies, see (b) F. H. Köhler and N. Hertkorn, ibid., 1983, 116, 3274; (c) M. Christl, H. Leininger, and D. Bruckner, J. Am. Chem. Soc., 1983, 105, 4843; (d) G. B. Trimitsis and P. Zimmermann, J. Chem. Soc., Chem. Commun., 1984, 1506.

6 N. Hertkorn, F. H. Köhler, G. Müller, and G. Reber, Angew. Chem., 1986, 98, 462.

7 R. Lindh, B. O. Roos, G. Tonsäll, and P. Ahlberg, J. Am. Chem. Soc., 1986, 108, in the press.

8 J. M. Brown, R. J. Elliot, and W. G. Richards, J. Chem. Soc., Perkin Trans. 2, 1982, 485.

9 M. J. S. Dewar and W. Thiel, J. Am. Chem. Soc., 1977, 99, 4899. Lithium parametrization: W. Thiel and T. Clark. W. Thiel, Quantum Chemistry Program Exchange 1983, 438. A listing of the MNDO parameters has been submitted to the QCPE News Letter.
10 See, e.g., P. v. R. Schleyer, Pure Appl. Chem., 1984, 56, 151; 1983, 55, 355; A.-M. Sapse, E. Kaufmann, P. v. R. Schleyer, and R. Gleiter, Inorg. Chem., 1984, 23, 1569; D. Wilhelm, T. Clark, and P. v. R. Schleyer, J. Chem. Soc., Chem. Commun., 1983, 211; E. D. Jemmis, J. Chandrasekhar, E.-U. Würthwein, and P. v, R. Schleyer, J. Am. Chem. Soc., 1982, 104, 4275; G. Boche, G. Decher, H. Etzrodt, H. Dietrich, W. Mahdi, A. J. Kos, and P. v. R. Schleyer, J. Chem. Soc., Chem. Commun., 1984, 1493; P. v. R. Schleyer and A. J. Kos, Angew. Chem., Int. Ed. Engl., 1984, 23, 620; P. v. R. Schleyer, A. J. Kos, and E. Kaufmann, J. Am. Chem. Soc., 1983, 105, 7617; R. A. Hagopian, M. J. Therien, and J. R. Murdoch, ibid., 1984, 106, 5753; M. L. McKee, ibid., 1985, 107, 859, 7284; G. Boche and H.-U. Wagner, J. Chem. Soc., Chem. Commun., 1984, 1591. Also see refs. 13 and 14.

11 P. v. R. Schleyer and A. J. Kos, Tetrahedron, 1983, 39, 1141.

12 J. Chandrasekhar, J. G. Andrade, and P. v. R. Schleyer, J. Am. Chem. Soc., 1981, 103, 5609.

13 (a) P. v. R. Schleyer, J. Am. Chem. Soc., 1985, 107, 4793; (b) T. Clark, C. Rohde, and P. v. R. Schleyer, Organometallics, 1983, 2, 1344; (c) G. Decher and G. Boche, J. Organomet. Chem., 1983, 259, 31; (d) G. Boche, H. Etzrodt, M. Marsch, W. Mass, G. Baum, H. Dietrich, and W. Mahdi, Angew. Chem., 1986, 98, 84.

14 P. v. R. Schleyer, A. J. Kos, and E. Kaufmann, J. Am. Chem. Soc., 1983, 105, 7617.

15 K. N. Houk, N. G. Rondan, P. v. R. Schleyer, E. Kaufmann, and T. Clark, J. Am. Chem. Soc., 1985, 107, 2821; J. E. DelBene, M. J. Frisch, K. Raghavachari, J. A. Pople, and P.v. R. Schleyer, J. Phys. Chem., 1983, 87, 73.

16 R. H. Staley and J. L. Beauchamp, J. Am. Chem. Soc., 1975, 97, 5920

17 W. N. Setzer and P. v. R. Schleyer, Adv. Organomet. Chem., $1985,24,353$; C. Schade and P. v. R. Schleyer, ibid., in the press.

18 Other possible homoaromatic anionic systems, where counterion effects have not been clarified by structural determinations ( $X$-ray or calculations), are reported by: M. J. Goldstein, S. Tomoda, and G. W. Wittaker, J. Am. Chem. Soc., 1974, 96, 3676; M. J. Goldstein, T. T. Wenzel, G. W. Wittaker, and S. F. Yates, ibid., 1982, 104, 2669; M. J. Goldstein and T. T. Wenzel, J. Chem. Soc., Chem. Commun., 1984, 1654, 1655; M. J. Goldstein and J. P. Barren, Symposia Preprints, Petroleum Division, Am. Chem. Soc., 1985, 30, 592; W. Huber, K. Müller, R. Busch, W. Grimme, and J. Heinze, Angew. Chem., 1982, 94, 298; Angew. Chem. Int. Ed. Engl., 1982, 21, 301. 